\title{
AQUISIÇÃO, AFASIA E A HIERARQUIA PROSÓDICA ${ }^{1}$
}

\author{
ESTER MIRIAN SCARPA \\ (IEL/UNICAMP)
}

\begin{abstract}
Studies on language acquisition have shown that the child exhibits a top-down trajectory in the acquisition of the prosodic hierarchy, starting with the organisation of the upper (intonational) prosodic levels. Rhythmic readjustments and postlexical secondary stress are later acquisitions. Prosodic disturbances of aphasia and dysarthria have been connected to the question of brain-damage lateralisation and linguistic processing. Subjects damaged in their right hemisphere are said to be dysprosodic; they produce few $F_{o}$ variations, $F_{o}$ flattenning, slow tempo. Prosody is said to be reasonably preserved in Broca's subjects and well preserved in fluent (Wernicke) aphasia subjects. A comparative study was carried out with two subjects, one aphasic and one dysarthric. Some prosodic difficulties were observed in the speech of fluent aphasic subjects, related to the prosodic hierarchy, to the metrical grid and to syllable structure, respectively. On the other hand, the correct placement of pauses in the frontiers of upper domains of the dysarthric subject shows preservation of the prosodic hierarchy. Pitch-direction is also preserved, with short pitch-range. In both cases, the upper domains of the prosodic hierarchy are preserved.
\end{abstract}

O estudo da fala de cérebro-lesados depara-se com a questão da medicalização da fala afásica, recorrente na literatura afasiológica. Uma fala é patológica? Como se dá a transposição da patologia da lesão cerebral para a atividade lingüística? As respostas a essas questões ultrapassam os limites do puramente lingüístico e do puramente cerebral, além de tocar necessariamente na delicada questão dos vínculos entre mente/cérebro e linguagem, por um lado, e no não menos delicado encontro da Lingüística com a campos científicos que tratam da patologia, de outro.

A área da Aquisição da Linguagem tem também sido, tradicionalmente, um daqueles campos que têm que contemplar os limites do diferente e do desviante. Afasia e Aquisição da Linguagem são áreas que acabam tocando nas franjas da normalidade lingüística. A afasia, por representar a "perda" de uma faculdade, capacidade, habilidade, ou qualquer nome que se queira dar à atividade lingüística, causada por lesão, e que atinge um sujeito que se supõe em pleno domínio ou exercício de tal faculdade. A aquisição, pelo caráter de presumida incompletude da plena posse da

${ }^{1}$ Versões preliminares deste artigo foram publicadas em Scarpa (2000) e Scarpa (no prelo); é ele o relato de reflexões sobre pesquisas em curso, objetivo propício dos encontros periódicos do Grupo de Trabalho em Psicolingüística da ANPOLL. Mais especificamente, o conteúdo deste relato tem a ver com o trabalho apresentado no XV Encontro Nacional da ANPOLL, na Universidade Federal Fluminense, em junho de 2000. Essas pesquisas têm se beneficiado de financiamentos parciais do CNPq, processo no. 301884/85 e da FAPESP, processo no. 1999/05355-2. 
mesma capacidade que representa a língua/linguagem da criança. São os dois desvios do conhecimento padrão da língua/linguagem (conhecimento sobre o qual as teorias lingüísticas se assentam) dignos de nota na teoria lingüística. Segundo Grodzinsky (1990), os desvios desse conhecimento se devem à falta de tempo, na criança; no afásico, ao fato de ele ter sido um bom representante da comunidade de falantes antes da doença.

Ora, é exatamente por tocar nas franjas da normalidade que a aquisição e a afasia apelam para a explicitação do lingüístico, da natureza da linguagem. Esta ponte tem chamado a atenção de estudiosos há bem mais de meio século, a começar pelo trabalho de Jakobson, sobre a aproximação entre aquisição e afasia, trabalho fundante desta linha que aproxima as duas pontas da normalidade através de considerações elucidativas sobre a própria linguagem. Refiro-me a considerações sobre o paralelo estabelecido por Jakobson e depois conhecido como "hipótese da regressão". Seu ensaio "Child Language, Aphasia and Phonological Universals", escrito nos anos $30 \mathrm{em}$ alemão, mas publicado em inglês em 1968, é um dos trabalhos fundadores dos modernos estudos afasiológicos, no que tange a uma abordagem lingüística propriamente ao fenômeno da afasia. Tem sido ponto de referência tanto para estudos sobre ordem da aquisição da fonologia quanto para a análise da perda lingüística em sujeitos afásicos. Neste ensaio, à afirmação de Buhler de que a linguagem da criança fornece a única oportunidade de observar a língua no seu estado nascente, Jakobson acrescenta a constatação de que os distúrbios patológicos da fala fornecem a única oportunidade de observar a língua em dissolução. A idéia de que o que é adquirido primeiro é que mais permanece nos afásicos em situação de perda ficou rapidamente conhecida como a hipótese do "espelho invertido", também chamada de "hipótese da regressão". Como argumentação inicial, Jakobson invoca o princípio da descontinuidade entre as emissões do balbucio e o sistema fonológico da língua materna, este adquirido no começo da produção das palavras semelhantes às do adulto. No balbucio, segundo ele, a criança é capaz de "acumular articulações" que não são encontradas numa só língua ou mesmo num grupo de línguas - consoantes de qualquer ponto de articulação, consoantes palatalizadas ou arredondadas fricativas, cliques, vogais complexas - percorrendo potencialmente todo o espectro vocálico e consonântico. Assim que as primeiras palavras aparecem, no entanto, a criança perde a habilidade de produzir toda esta gama de sons. Não só sons que não estão presentes na língua da comunidade da criança desaparecem do seu inventário, como também muitos sons que são comuns ao balbucio e à língua da comunidade também ficam faltando, pelo menos transitoriamente, do seu repertório. Começa, então, uma certa progressão definida em termos de ordem de aquisição de distinções opositivas, fonemáticas, de tal maneira que os contrastes/ oposições que são mais comuns nas línguas aparecem primeiro (segundo o princípio de mínimo consonantismo e mínimo vocalismo) e aquelas que são menos atestadas nas línguas aparecem mais tarde (contraste no sistema de líquidas, distinção entre chiantes e sibilantes, por exemplo). Na afasia, a perda de distinções seriam ordenadas, de acordo com a hierarquia existente entre traços distintivos na fonologia "normal". Esta ordem é observada na criança adquirindo a 
linguagem, embora na direção oposta. A hipótese do espelho invertido ou da regressão é estendida, por Jakobson, para as categorias gramaticais.

A hipótese da regressão foi retomada mais recentemente, no âmbito da gramática gerativa, no estudo do agramatismo. Grodzinsky (1990) vincula tal hipótese à eficácia explicativa do Princípio do Subconjunto de Berwich em Aquisição da Linguagem, que propõe que a gramática da língua L é necessariamente um subconjunto da GU; nos estágios de aquisição, as possíveis gramáticas sucessivas da criança (S1, S2...) são subconjuntos da gramática Sn isto é, do adulto. Assim também, a lingua do afásico nunca pode ser maior que a língua do estágio final da aquisição, isto é, a língua "normal" do adulto, que o afásico dominava antes da lesão cerebral (uma visão de "superconjunto"). Segundo esta hipótese, na afasia, síndromes afásicas e graus de severidade reproduziriam, inversamente, certas regularidades da aquisição da gramática da língua. Assim, quanto menor a gramática (ou a língua), mais severo é o déficit. Sua perda é um subconjunto da gramática de sua língua. O Princípio do Subconjunto tem sido ignorado nos estudos de aquisição da linguagem e a hipótese da regressão ainda é uma questão em aberto. Não há ainda um corpo de evidências gramaticais conclusivas a ela (os dados de afasia são esparsos), nem há argumentos fortes o suficiente para descartá-la como irrelevante.

Por outro lado, a hipótese da regressão exerceu impacto duradouro na comunidade clínica e acadêmica que, direta ou indiretamente, trabalha com as chamadas "patologias da fala ou da linguagem" da criança. Mais ainda, tal hipótese rapidamente lançou na comunidade de pesquisadores a assunção de que a prosódia é uma dos primeiros elementos lingüísticos que a criança adquire e a única (última?) possibilidade expressiva que sobra aos afásicos. No entanto, como sói acontecer com as afirmações que pertencem ao senso comum, seu sentido é pouco compreendido. Em primeiro lugar, no âmbito das comunidades clínicas e acadêmicas que se voltam para o estudo das chamadas "patologias da fala ou da linguagem", o estatuto relacional do valor lingüístico das oposições fônicas em termos de traços distintivos foi rapidamente reinterpretado através de uma visão equivocada e ingênua de "ordem de aquisição de fonemas", num apelo à empiria explicitamente negada por Jakobson.

Por outro lado, se a referência à prosódia na fala de pacientes cérebro-lesados tem contribuído para o discurso fundador da moderna afasiologia lingüística e para a reinvidicação do espaço da teoria e análise lingüística como um dos polos interdisciplinares deste estudo, o fato é que hoje pouco se sabe sobre a situação prosódica das afasias.

E como tem sido o tratamento dispensado à prosódia na literatura afasiológica?

Os distúrbios prosódicos da afasia e disartria, na literatura da área, tem sido vinculados à questão da lateralização da lesão e, conseqüentemente, do processamento lingüístico ${ }^{2}$. Termos e conceitos estabelecidos para as dificuldades prosódicas de cérebro-lesados tornaram-se aceitos sem grandes discussões, embora sejam de adequação explicativa quase nula: aprosódia ("falta" de prosódia); hiperprosódia ("uso excessivo" de prosódia). A hipótese da lateralização hemisférica do processamento

\footnotetext{
2 Já notado por Morato \& Freitas 1993.
} 
prosódico, (segundo a qual a prosódia "lingüística" é processada no hemisfério esquerda ao passo que a prosódia "afetiva" processa-se no hemisfério direito) transferese para o déficit. A idéia básica é que os sujeitos lesados no hemisfério direito não produzem satisfatoriamente o que a literatura chama de "prosódia afetiva": apresentam poucas variações de $\mathrm{F}_{\mathrm{o}}$, achatamento na tessitura; fala lentificada. Já afásicos lesados no hemisfério esquerdo teriam dificuldade de processar a prosódia responsável pela estruturação interna das sentenças. A lateralização da lesão e sua relação com a prosódia tem tido novas roupagens, sempre na dependência da concepção que o pesquisador tem da prosódia propriamente. Assim, propõe-se que o processamento prosódico obedeça a uma escala funcional, segundo a qual o contraste de altura progride do eixo "mais lingüístico" ao eixo "menos lingüístico" (Moer \& Sundet 1996). O processamento hemisférico depende da posição do uso dos contrastes de altura nesta escala funcional, como ilustra a figura abaixo.

Hemisf. Esquerdo

Hemisf. Direito

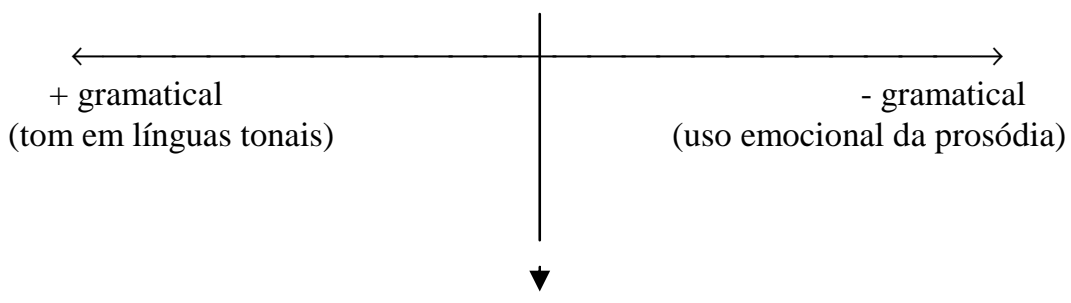

\section{bilateralização \\ (entonação lingüística)}

Fig. 1. Escala de contraste de altura segundo suas funções.

Quanto "mais lingüística" ou "mais gramatical" for a função da altura, mais inserida dentro de um processamento no hemisfério esquerdo ela estará e, vice-versa, quanto "menos lingüística" ou "menos gramatical" for o parâmetro de altura (por exemplo, entonação dita "afetiva"), mais será ela candidata a ser processada pelo hemisfério direito, junto com a música e a experiência estética.

$\mathrm{O}$ grande problema com esta escala reside na dificuldade de se decidir onde traçar uma linha demarcatória entre as várias funções da altura, porque a escala representa um contínuo funcional e não uma sucessão de funções discretas. E aí eles tocam na questão central lingüística do conceito de prosódia e do conceito de suas próprias funções lingüísticas: é inegável que a palavra "emotiva" para qualificar certos aspectos prosódicos é pouco explicativa, se não pré-teórica. Mais ainda: se as interfaces entre a prosódia e outros componentes lingüísticos se dão ao mesmo tempo, quais são os critérios usados para separá-las assim de maneira tão compartimentada? E onde traçar o limite entre o "lingüístico" e o "não-lingüístico"?

Assim, resumidamente, pode-se apontar dificuldades teórico-metodológicas no tratamento que a literatura dá aos chamados "distúrbios prosódicos" em duas frentes: 1) a doença e a lateralização; 
2) a visão de língua e a decorrente visão de prosódia constante na literatura.

De tal maneira são questionáveis estes dois temas tal como são tratados, que necessário se faz rever tratamentos e dados. Além disso, o caráter difuso e elusivo das manifestações lingüísticas da afasia têm que ser levado em conta: diferenças individuais desafiam posturas que advogam tanto dicotomia estrita de especialização hemisférica quanto de concepção lingüística/ não lingüística de prosódia.

Tendo em mente colocar em questão a localização de processamento por hemisfério dos distúrbios prosódicos é que selecionei dados de dois sujeitos cérebrolesados, cujos deficits são associados a etiologias diversas: um é classificado na literatura como portador de afasia de seleção ou "de Wernicke" (SB) e outro cujo diagnóstico neurolingüístico classifica-o como disártrico (LC) ${ }^{3}$.

Seguem, resumidamente, os resultados a que tenho chegado.

\section{DIFICULDADES PROSÓdiCAS NA FALA DE SUJEITO PORTADOR DE AFASIA DE SELEÇÃO (SB).}

Os padrões de $F_{o}$ nos sujeitos lesados no hemisfério esquerdo encontram-se, segundo a literatura (ver Code 1988; Wernige 1993), razoavelmente preservados, com bom índice de reconhecimento de variações de altura. Já aqueles portadores de afasia causada por lesão no hemisfério direito têm dificuldade em reconhecer o que é chamado de entonação emocional.

O sujeito analisado, SB, é portador de afasia de Wernicke. Neste tipo de afasia, acredita-se, a altura, o acento e a duração encontram-se bem preservados, com exceção de algumas características que podem distinguir a fala de alguns sujeitos assim afásicos da de sujeitos não cérebro-lesados. A divisão do enunciado em unidades menores é mais frequente do que em sujeitos normais ((Danly, Cooper \& Shapiro 1983), além do que tais sujeitos afásicos exibem uso mais frequente de " $F_{o}$ resetting": iniciar um novo contorno entonacional ou uma nova fronteira prosódica depois de uma fronteira sintática maior. Além disso, há mais curvas ascendentes de "continuação". As causas possíveis destas modificações são, segundo os autores:

- um deficit na programação de baixa escala de unidades lingüísticas;

- perda de controle fonatório.

${ }^{3}$ SB é afásica, em decorrência de lesão posterior. Sofreu um acidente cerebral isquêmico na região têmporo-parieto-occiptal esquerda aos 47 anos. Sua afasia é do tipo acústico-amnésica , segundo classificação luriana, ou "de Wernicke", ou ainda "fluente". A afasia deste tipo é caracterizada pela dificuldade de acesso lexical e pela produção de parafasias fonológicas e semânticas, que resultam no que a literatura convenciona chamar de "neologismos". Os sujeitos assim afásicos podem exibir um certo paragramatismo, como a preferência por nomes e nominalizações a verbos: há a tendência freqüente de elidir os verbos ou a substituí-lo pelo nome ou expressão nominalizada correspondente, atestada ou não na língua. Além disso, tais afásicos exibem dificuldades com a produção e o processamento de papéis temáticos do verbo.

LC apresenta uma lesão traumática no hemisfério direito, aos 19 anos. Segundo Felizatti (1998), os indivíduos com lesão neste hemisfério não são propriamente afásicos: não apresentam o sistema lingüístico comprometido em termos de seus níveis (fonológico, sintático, semântico, pragmático). Por outro lado, podem manifestar déficits que afetam a expressão prosódica, lentificação evidente na velocidade de fala. 
Outras explicações, de natureza prosódica, podem ser possíveis para este caso ${ }^{4}$ e explicar alguns dos neologismos presentes em sua fala.

Foram detectadas 3 dificuldades interligadas nos dados do sujeito em questão:

$1^{\text {a) }}$ freqüentes divisões ou fatiamento do enunciado entonacional em frases entonacionais (ou grupos tonais).

$2^{\text {a }) ~ r e a r r a n j o s ~ m e ́ t r i c o s ~ d e ~ p a l a v r a s ~ d e v i d o s ~ a ~ a j u s t e s ~ r i ́ t m i c o s ~ p o ́ s-l e x i c a i s ; ~}$

$3^{a}$ ) simplificação da estrutura silábica: não-ramificação de ataques silábicos (onsets).

\section{Primeira dificuldade}

Para melhor descrição desta primeira dificuldade, é útil retomar os modelos de fonologia prosódica e respectivos níveis hierárquicos. Retomo, brevemente, o esquema de hierarquia prosódica de Nespor \& Vogel 1986 ( ver figura 1).

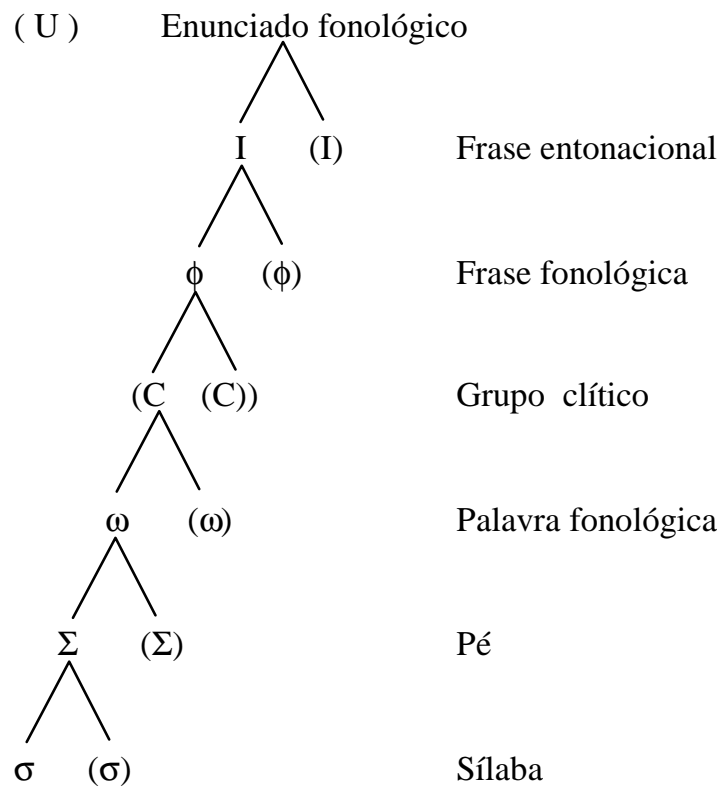

Fig. 2. Hierarquia prosódica (Nespor \& Vogel 1986).

O enunciado fonológico pode, em teoria, ser dividido em unidades menores (frase entonacionais) até o limite de uma sílaba, seguindo critérios fonéticos e semânticos de

${ }^{4}$ Deve-se sempre ter em mente uma das características fundamentais da pesquisa com dados de afasia a extrema variabilidade da fala dita afásica e o caráter fugidio da taxonomia lingüística das afasias. Cada afásico é um caso e muitas vezes um "erro" já descrito simplesmente desaparece em outros dados. 
segmentação do enunciado. No entanto, as fronteiras entre unidades entonacionais tendem a ser inseridas dentro de fronteiras maiores sintáticas e entre fronteiras prosódicas que coincidam com frases entonacionais ou grupos clíticos. $\mathrm{Na}$ fala conectada, com velocidade de fala normal, no entanto, enunciados como (1a) a (1c) são mais comuns do que (1d) a (1e):

(1a) [[Todo mundo] $\phi$ [foi à praia $] \phi[$ ontem à noite $] \phi] \mathrm{I}$

(1b) [Todo mundo] I [foi à praia ontem à noite] I.

(1c) [Todo mundo foi à praia] I [ontem à noite] I.

(1d)(?) [Todo mundo foi] I [à praia ontem à noite] I .

(1e)(??) [Todo] I [mundo foi à praia ontem à noite] I

(1f) [Todo] I [mundo] I [foi] I [à] I [praia]I [ontem] I [à] I [noite] I.

1d, 1e e 1f, em que fronteiras prosódicas são criadas dentro de domínios sintáticos ou prosódicos maiores, seriam possíveis, mas usados em situações restritas e pragmaticamente marcadas: $1 \mathrm{~d}$ e $1 \mathrm{f}$ seriam interpretados como relacionados a uma fala didática ou paternalista; 1e seria visto como contendo uma pausa de hesitação, em que a próxima palavra seria alvo de acesso delongado.

Enunciados longos, como (2)

(2) Josefina descobriu que seu quintal foi invadido no mês passado por uma multidão de gatos pardos.

são mais aceitáveis, com relação a uma divisão interna de unidades entonacionais, se forem pronunciados com um velocidade média ou ligeiramente acelerada de fala, em (2a) do que em (2b).

(2a) [[Josefina] $\phi$ [descobriu] $\phi$ ] I [ [que seu quintal] $\phi$ [foi invadido] $\phi$ [no mês passado] $\phi] I$ [por uma multidão] $\phi$ [de gatos pardos.] $\phi] \mathrm{I}$.

(2b) [Josefina] I [descobriu] I [que seu quintal] I [foi invadido] I [no mês passado] I [por uma família] I [ de gatos pardos] I.

(2b) seria bastante apropriado, por exemplo, num contexto de leitura de um texto para crianças, ou com um tom professoral ou didático.

Em outras palavras, a divisão do enunciado em unidades entonacionais menores (também chamadas de "unidades de informação") é possível, mas obedece a certas pressões significativas reconhecíveis. O rearranjo entonacional do enunciado é um rearranjo de significantes, é o estabelecimento de fronteiras formais que veicula significados diversos.

O que faz o sujeito afásico observado?

Observou-se um número bastante elevado de divisões do enunciado em unidades entonacionais menores, sobretudo quando o verbo - um dos maiores alvos de dificuldade de acesso lexical - está elidido. Os dois exemplos abaixo, (3) e (4) ilustram este caso:

(3) [Sabu (sabado)] I, [a mulher] I // [sopa] I.

Possível alvo:

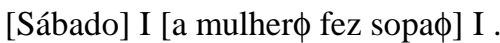


(4) [Veio] I, [pessoal] I, [sopa], I [da escola] I(...) [Abraço] I, [muito] I. Alvo possivel:

[[Veio] $\phi[$ o pessoal] $\phi]$ [da sopa] $\phi]$ I, [na escola] $\phi]$ I. [[Me abraçaram muito] $\phi]$ I.

Esta espécie de upgrading de frases fonológicas para frases entonacionais é bastante comum na fala deste sujeito, mesmo quando o significado criado não é o de um estilo didático.

\section{Segunda dificuldade}

A segunda dificuldade apresentada pelo sujeito tem a ver com reajustes rítmicos em nível pós-lexical. Vejamos, primeiro, o que é uma grade métrica e no que consistem ajustes rítmicos no nível da frase fonológica.

A grade métrica dá conta do ritmo da sentença, através da proeminência relativa de sílabas sucessivas, marcada por um asterisco em linhas e colunas para as sílabas fortes. Assim, a proeminência é indicada na relação entre sílabas fortes e fracas. As sílabas não são agrupadas diretamente em palavras, mas são primeiro agrupadas em constituintes intermediários, os pés. A maior parte dos argumentos em favor do pé na teoria métrica são baseados em atribuição de acento primário, de palavra. Uma sílaba é etiquetada de forte ou fraca no nível do pé.

Ver, por exemplo, como seria a grade métrica do enunciado (5):

$[[[$ Muita $] \omega[$ gente $] \omega] \phi[[$ sente $] \omega[$ medo $] \omega] \phi] I$

\begin{tabular}{|c|c|c|c|c|c|c|c|c|}
\hline & & & & & & $*$ & & L3 (nível 3) \\
\hline & & $*$ & & & & $*$ & & L2 (nível 2) \\
\hline$*$ & & $*$ & & $*$ & & $*$ & & L1 (nível 1) \\
\hline$*$ & $*$ & $*$ & $*$ & $*$ & $*$ & $*$ & $*$ & L0 (linha de base) \\
\hline Mui & ta & gen & te & sen & te & me & do & \\
\hline
\end{tabular}

Ora, as línguas têm tendência à eurritmia (também chamada de "grade perfeita"), à alternância rítmica (forte-fraco) e a evitar colisões acentuais (isto é, dois acentos fortes sucessivos no mesmo nível métrico acima da palavra prosódica ou fonológica). Entre as possíveis soluções à colisão acentual, contam-se: movimento de altura, regras de desacentuação, retração acentual (ou reversão iâmbica), adição de batida, regras de sândi externo, apagamento ou síncope de parte(s) da sílaba e conseqüente ressilabificação, etc. Algumas dessas regras são categóricas, outras são regras variáveis, facultativas. Mas o que é comum a todas elas é que são específicas de cada língua (e não universais). Eis um exemplo clássico, extraído de Selkirk (1984), que ilustra reajustes rítmicos (no caso, retração acentual ou reversão iâmbica) como solução a colisão acentual: 
(6) Thirteen mén.

$\begin{array}{ccccccc} & * & * & * & * & & * \\ * & * & * & & * & * & * \\ \text { thir téen } & \text { mén } & & \text { thír teen } & \text { Mén } \\ \text { (colisão acentual) } & & & \text { (retração acentual) }\end{array}$

Assim também:

(7) Tènnessée áir $\Rightarrow$ Ténnesee áir

(8) [More than] [fiftéen cárpenters] [are working] [in the house]. $\Rightarrow$ fífteen cárpenters

Como o domínio da colisão acentual é o da frase fonológica $(\phi)$, Nespor \& Vogel (1986) atribuem a tais reajustes a função de reestruturação de frase fonológica. Além disso, um outro traço prosódico - velocidade de fala - também contribui para mudanças e reajustes na grade.

O sujeito afásico, $\mathrm{SB}$, implementa determinadas soluções rítmicas inesperadas às frases fonológicas, fazendo resultar disso a impressão de desarranjo métrico em seqüências que a literatura tem interpretado como parafasia (palavra inventada no lugar da palavra-alvo) e neologismo.

Eis alguns exemplos:

(9) O padre gou pra mim.

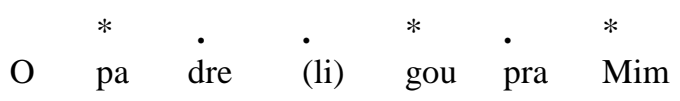

(10) São José do Pardo

(11) São José dio Pardo.

A explicação métrica para a produção de (10) e (11) é, respectivamente:

* . $\{* *\}$ colisão acentual

São José do // (Rio) Pardo (apagamento da sílaba forte) $\Rightarrow$ São José do Pardo.

São José d(o R)io Pardo (ressilabificação incomum e rearranjo de pé) $\Rightarrow$ São José dio Pardo.

Neste caso, a desacentuação seria mais esperada:

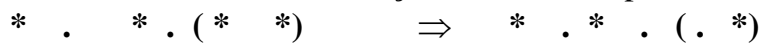

São José do Río Párdo São José do Rio Párdo

Prova de que nem sempre os reajustes são os esperados é o enunciado (12), em que o sujeito recusa um trecho de "grade perfeita", à qual nenhum reajuste seria necessário, por não apresentar colisão acentual: 
(12) le(ite) condensado .

A esperada seqüência eurrítmica para o português seria a sucessão de 3 troqueus *.*.*. (léi-te-cón-den-sá-do). Tal sequiência se configuraria numa "grade teoricamente perfeita", por respeitar estritamente o princípio (que se quer universal) de alternância rítmica. No entanto, é recusada em prol de um dátilo (*..) e um troqueu (*.), seqüência igualmente aceita em grupos rítmicos do português brasileiro. No caso da solução encontrada, porém, o resultado é a impressão auditiva de fala truncada, na produção do afásico.

Palavras isoladas não exibem problemas rítmicos, em teoria: a colisão acentual só existe, por definição, em níveis métricos acima da palavra. Neste caso, a busca por um troqueu canônico, pé preferencial do português, é a solução ótima encontrada e não um dátilo (13), ou dois troqueus (14) ou uma seqüência fraco-forte-fraco (15), perfeitamente encontráveis em palavras da língua, como se pode ver nos enunciados abaixo.

(13) médus por médicos

(14) crito por acredito.

(15) minas por meninas

Resumindo: A solução rítmica encontrada pelo sujeito é uma seqüência métrica défault trocaica (forte-fraco) para as palavras isoladas e pés derivados de reajustes métricos pós-lexicais, com opção por apagamento de sílabas e ressilabificação para palavras em contexto de frase fonológica.

Este comportamento prosódico é compatível com o tipo de dificuldade presente na afasia do sujeito: restrição a acesso lexical, em que a palavra não se encontra prontamente disponível. Além disso, boa parte das suas parafasias acontecem em situação de repetição de palavras ou sílabas. Algumas observações da literatura interpretam esta dificuldade como sendo perceptual-acústica. Antes de serem problemas perceptuais e muito menos acústicos, as parafasias acontecem em palavras isoladas em atividades e tarefas metalingüísticas, como repetição para efeito de teste ou terapia.

Para que o sujeito efetue os ajustes métricos favorecidos pela sua língua, ele teria que saber a métrica original da palavra para processar corretamente a interação entre a palavra e a frase fonológica; isto, é, para "subir" na hierarquia métrica. Como a palavra - e sua estrutura métrica - não estão prontamente disponíveis, uma solução genérica típica de frase fonológica é dada - e não necessariamente uma que seja compatível com a sequiência segmental envolvida. Daí estranhas ressilabificações. Daí pelo menos parte das parafasias e do que se chama, muito equivocadamente, de "neologismos".

Segundo estudos de Nickels \& Howard (1999), os sujeitos afásicos cometem mais erros repetindo seqüências fraco-forte do que forte-fraco. Os erros nas palavras com padrão fraco-forte envolvem a omissão da sílaba não acentuada (romance $\Rightarrow$ mance). Levantam a hipótese de que, na falta de acesso à forma fônica da palavra, uma seqüência forte-fraco é gerada e aplicada como défault à forma segmental produzida. 
Esta hipótese explica parte de nossos dados, mas não explica casos em que a sílaba tônica é elidida (10) ou ressilabificada e desacentuada (11). Uma explicação que aponta para estratégias de buscar recursos métricos num nível acima da hierarquia prosódica e, assim, recorrer sempre aos níveis "superiores" do enunciado pode dar conta melhor das duas dificuldades observadas. Recorrer a estruturas prosódicas de níveis superiores significa que o afásico está sempre recorrendo a traços presentes no enunciado, perto da superfície e do discurso, na falta de recursos estruturais lexicais.

\section{Terceira dificuldade}

A terceira dificuldade tem a ver com a redução na estrutura silábica, através da não-ramificação de ataques silábicos (onsets) ocupados por plosiva + líquida. A líquida é elidida, gerando um ataque não ramificado, como se pode ver em (16) e (17).

(16) tiste $<$ triste

(17) lembo < lembro.

É interessante notar a volta a uma espécie de "árvore mínima” na estrutura silábica $(\mathrm{CV})$, como é comumente reportado na fala inicial, inclusive no português.

\subsection{Dificuldades prosódicas do sujeito disártico (LC) ${ }^{5}$}

A disartria deste sujeito caracteriza-se por lentificações generalizadas de sua fala, por causa de limitações psicomotoras a nível cerebelar. Tais lentificações na velocidade de fala acompanham um grau razoável de neutralização da duração silábica, o que resulta num desarranjo rítmico dos enunciados, já que a estrutura de pés métricos parece resultar neutralizada e a sílaba tônica da palavra nem sempre é mais longa que as átonas. Numa primeira medida de duração, a leitura de um trecho de cerca de 40 palavras (22) demandou 55 segundos por parte de LC, comparada ao tempo de leitura de 15 a 20 segundos por sujeito adulto não cérebro-lesado. A neutralização, em várias partes do enunciado, entre sílabas longas e breves devido à velocidade de fala diminuída, propicia, como consequiência, fala silabada, encadeada e alongada (isto é,

\section{${ }^{5}$ Legenda.}

As seguintes notações foram usadas na análise dos dados.

// fronteira de unidade entonacional, com pausa.

/ pausa

][ fronteira de unidade entonacional, sem pausa.

$\nearrow$ Tom nuclear, tendência terminal ascendente.

$\searrow$ Tom nuclear, tendência terminal descendente.

$\rightarrow$ Tom nuclear, tendência terminal nivelada.

, Acento secundário (de frase), tom baixo.

'Acento secundário (de frase), tom alto.

$\uparrow$ Subida no contorno entonacional, em sílabas não-nucleares.

$\downarrow$ Descida no contorno entonacional, em sílabas não- nucleares.

\{ Fala simultânea com a do interlocutor. 
não staccatto). No entanto, segundo Felizatti (1998), em testes perceptuais, em que acompanha a duração relativa das sílabas átonas e tônicas com o uso de um apito, demonstra discriminar entre sílabas longas e breves de sua própria fala e da fala de seu interlocutor.

Outra característica prosódica é a maximização de pausas. Há poucas pausas de hesitação e de busca por uma palavra no seu léxico mental. A inserção das pausas obedece a fronteiras prosódicas dos constituintes prosódicos acima da palavra. Exatamente igual ao que acontece em certos estilos orais de fala pausada, silabada da fala do adulto não-disártico falante nativo do $\mathrm{PB}$, como é o caso da pesquisadora que o entrevista. Nos excertos (18), (19) e (20), nota-se a mesma estratégia de colocação de pausas partilhada pelo sujeito e pela sua terapeuta. A diferença é que o grande número de pausas da fala da entrevistadora se deve a uma escolha estilística, ao passo que o grande número de pausas na fala de LC é um traço constitutivo de sua fala. LC vê reduzidas suas opções estilísticas em discursos que criam significado fazendo uso de variações na qualidade de voz e na velocidade de fala.

Os dados abaixo mostram que a inserção de pausas na fala de LC não é, de modo algum, um processo caótico. Demonstra conhecimento de fronteiras prosódicas.

(18) PF. Por que o anão Atchim não estava com a Branca de Neve?

LC. Aqui não menciona.

PF. Menciona, sim.

LC. Ele foi/ comprar/ alguma/ coisa.

E na volta/ aconteceu/ isso.

\section{Lendo:}

(19) LC. ,Respon $\uparrow$ deu / Branca de $\searrow$ Neve// $\uparrow$ Não se preo $\searrow$ cupe // Al $\uparrow$ guém tocou a campa $\searrow$ inha//, avisou o Fe $\searrow$ liz// Mestre a $\uparrow$ briu/ a $\searrow$ porta.][ E A $\searrow$ tchim // en $\nearrow$ trou// quase sem $\searrow$ fôlego.// ${ }_{1} \mathrm{Su} \nearrow$ ando,][ $\downarrow_{\text {to }} \nearrow$ ssindo// e espi $\searrow$ rrando.// $\uparrow$ Eu corri o ca'minho atrás de um $\searrow$ ônibus.][ ,Com dificul $\nearrow$ dade,// economi ' zei a pa $\searrow$ ssagem.

\section{Fala corrente, espontânea:}

(20) LC. 'Disse Atchim/ pra $\nearrow$ ele][ \não// pe $\uparrow$ gasse um $\searrow$ taxi// ele se $\nearrow$ ria // ele se $\nearrow$ ria, $][\searrow$ não.// eles economiza $\uparrow$ riam 'muito $\searrow$ mais.//

O trecho em itálico, que poderia ser interpretado como repetição pouco significativa e prosodicamente inadequada, é, de fato, uma auto correção. Prosodicamente, apresenta uma frase encaixada, constituindo duas unidades entonacionais sem pausa entre elas, utilizando a mudança de contorno para delimitar fronteira de unidade entonacional.

Compare sua fala com a da investigadora, num trecho pausado e "didático", isto é, com velocidade de fala diminuída:

PF. E o que 'tem/ a ver/ falar/ da Branca de $\downarrow$ Neve em $\searrow$ Londres?// 
PF. Na verdade,// o que que aconteceu,][ Luís?] // Sem/ mencionar o texto/ inteiro// né// o que que aconteceu?// Um anão/ chegou/ na casa/ deles ][ né// em Londres // e falou o quê? Chegou correndo,// suando, // não é?// e disse que/ pra economizar o dinheiro// ele vol $\rightarrow$ tou...//

LC. ,A $\nearrow$ pé...//

PF. ,A $\nearrow$ pé,// , co $\nearrow$ rrendo// atrás de $\nearrow$ um...// $\searrow$ ônibus.//

LC. $\quad\{, \operatorname{co} \nearrow$ rrendo $\quad\{\searrow$ ônibus.//

É de se observar que a inserção de várias unidades entonacionais, cujas fronteiras são ou não marcadas por pausa, pode ser uma estratégia discursiva utilizada por parte do falante. É o que PF está fazendo nos seus enunciados acima.

LC tem dificuldades rítmicas, que se manifestam na implementação fonéticoarticulatória das especificações de duração. Tanto é que ele não reduz as vogais átonas finais, uma das pistas de se considerar o PB como língua de "ritmo silábico", como, de fato se nota no seu dialeto, compartilhado pela pesquisadora que o entrevista.

Outra conseqüência, traduzida em termos de teoria métrica, é a dificuldade métrica, pós-lexical, de ajustes ritmicos dos pés dos enunciados. Daí que a qualidade ou timbre vocálico compatível com as alternâncias rítmicas da estrutura de pés do PB ficam alteradas. As alternâncias fraco-forte ficam razoavelmente apagadas na sua fala corrente, mesmo que ele as discrimine em testes de percepção. Por outro lado, a duração maior e mais saliente de uma sílaba forte com relação a outra, fraca, é muito mais preservada em sílabas portadoras do acento nuclear da unidade entonacional. A hierarquia de acento métrico é mantida; os domínios superiores da hierarquia prosódica são preservados na sua fala. É também digno de nota que a declinação - decréscimo de $F_{o}$ no final dos enunciados, o que pode fornecer pistas de fronteira prosódica - é mantida nos enunciados de LC, inclusive com a introdução de uma qualidade rangida de voz. Este último fato indica índices de $\mathrm{F}_{\mathrm{o}}$ reduzidos.

Resumindo: muitos aspectos da estrutura entonacional do enunciado encontra-se mantida neste sujeito, o contrário do pessimismo reportado na literatura.

As dificuldades relatadas acima são constantes na fala de LC, por uma questão de implementação articulatória das estruturas prosódicas, ao passo que as dificuldades da fala de SB são esporádicas, não constantes e não-previsíveis, o que é, aliás, uma das características marcantes da afasia.

\section{CONCLUSÕES}

Há semelhanças e diferenças entre SB e LC. A alternância rítmica e a redução de tessitura é o grande problema da fala de LC. São os aspectos prosódicos que lhe trazem os maiores problemas de comunicação, exatamente porque a fala monotônica e monorrítmica mascaram a expressão de mecanismos significativos dialógicos, discursivos e marcação de subjetividade. Deste ponto de vista, a interface entre a prosódia e os aspectos dialógicos/discursivos está comprometida. No entanto, o conhecimento estrutural da gramática prosódica está preservado. 
Já a dificuldade rítmica, não constante, da fala de SB tem a ver com redução silábica e ressilabificação pós-lexical, devidas a dificuldades com o acesso lexical. Quando o sujeito vai recorrer a níveis frasais métrico-prosódicos para compensar as dificuldades com acesso lexical, nem sempre as soluções são as corretas. Isto porque a interação entre léxico e sua estrutura métrica, entre acento primário e secundário, e entre o nível métrico da palavra fonológica e o da frase entonacional estão desarticuladas. Um falante tem que saber as fronteiras da palavra para poder empreender modificações prosódicas e processos fonológicos que ocorrem dentro dos domínios superiores. Se este conhecimento está perdido, a métrica da frase tem que ser restabelecida. As soluções encontradas são aquelas previstas pela língua, mas nem sempre as adequadas para cada caso.

Sua dificuldade em repetir palavras, sílabas e segmentos isolados também têm a ver com o estranhamento aos níveis inferiores da hierarquia prosódica. Seu julgamento metalingüístico fica comprometido pelo estranhamento do sujeito à sua própria fala.

A dicotomia de especialização hemisférica pode ser enganosa. Depende do conceito de prosódia que os autores têm. Em geral, apresentam uma visão ultrapassada e ingênua de entonação, mesmo em artigos publicados recentemente. Enxergam modulações de altura como paralingüísticas, prosódia como comunicação não-verbal e se esquecem que elementos paralingüísticos como os "settings", previstos por Laver (1980), que se classificam como "qualidades de voz", são largamente responsáveis pelo que classificam como "emoção". Confundem o uso dos parâmetros acústicos para a configuração da qualidade de voz, que veiculam o que os autores chamam genericamente de "emoção" ou "afeto", com o uso da entonação lingüística.

Por outro lado, chamam de "emoção" ou "afetividade" o que pode ser melhor interpretado, em modelos de análise de discurso e teoria da enunciação, como marcas de subjetividade na fala analisada. Esta última interpretação oferece vantagens pelo fato de melhor se equacionarem certas questões como a relação do sujeito com sua língua modificada, com o outro e com a própria doença.

Se se olharem os dados com uma visão prosódica baseada em princípios de fonologia prosódica, percebe-se que os dois sujeitos têm pontos em comum e pontos divergentes no tocante ao seu déficit prosódico. Ambos apresentam um quadro topdown de manutenção de domínios prosódicos superiores. SB apresenta dificuldade com o uso de sílaba e palavra isolada, o que é compatível com a classificação Jakobsoniana de afasia de seleção. É compatível também com um quadro de desarranjo segmental de seleção (e não de contiguidade ou fonotático) em casas segmentais previstas por categorias silábicas, dentro do ataque, da rima e da coda. Apresenta certas estratégias prosódicas, como sons preenchedores e jargões. Mas o que mais salta à vista é que, em decorrência de sua dificuldade de acesso lexical, os níveis que vão da palavra fonológica e descendo até a sílaba ficam comprometidos quando a dificuldade surge.

Deve-se sempre ter em vista que estas dificuldades não estão presentes o tempo todo na sua fala, sobretudo em trechos longos de fala conectada. Todos os níveis de acento são preservados, do pé à palavra, à frase fonológica, à frase entonacional. As dificuldades prosódicas experienciadas por este sujeito parecem afetar os níveis inferiores da hierarquia prosódica e as soluções encontradas são recursos métricos 
buscados em níveis prosódicos acima da palavra. Pode-se dizer que o sujeito está sempre recorrendo a níveis mais "enunciativos" ou mais próximos ao enunciado prosódico para superar uma dificuldade estrutural.

Outra necessária revisão é a do conceito de "neologismo" imputado aos afásicos de Wernicke, como SB. É quase consenso na literatura que o paciente assim afásico (afasia dita "fluente") lança mão de neologismos e isto se assume como classificável no nível semântico. Ora, vários "neologismos" encontrados na fala de SB revelam mais um desarranjo prosódico (manutenção do domínio prosódico superior, dificuldades nos inferiores) através de jargões que são sons preenchedores. Outra observação a ser feita diz respeito à inadequação do termo "neologismo", tirado do jargão lingüístico que trata de criações lexicais. Neologismos, em lingüística, refere-se a termos emprestados de outras línguas para preencher funções ou significados lexicais faltantes na língua. Uma vez incorporados, tais neologismos tornam-se produtivos e se integram às características estruturais fonológicas, morfológicas e sintáticas da língua. Não é o que ocorre com as palavras ou expressões da fala do afásico, igualmente chamadas de "neologismos" pela literatura afasiológica. São termos ou expressões fugidias, provisórias, cuja ocorrência dificilmente é previsível. Veja que SB produz, ao lado de

São José do Pardo, suas variáveis

São José dio Pardo

$\mathrm{e}$

São José do Rio Pardo.

Se a fala modificada tanto de LC quanto de SB demonstram que os domínios superiores prosódicos continuam intactos em ambos os casos, e se a criança segue uma trajetória de aquisição top-down no que concerne a hierarquia prosódica, então a hipótese de Jakobson se mantém: a "perda" é o espelho invertido da "aquisição". Para que se chegue a esta conclusão, porém, é mister que se revejam tanto os conceitos de lateralização hemisférica na literatura afasiológica, quanto o que a mesma literatura chama de "prosódico".

\section{$\overline{\text { REFERÊNCIAS }}$}

CODE, C. (1988). Language, aphasia and the right hemisphere. Londres, John Wiley and Sons.

DANLY, M., COOPER, W.E. \& SHAPIRO, B. (1983). Fundamental frequency, language processing, and linguistic structure in Wernicke's aphasia. Brain and Language, 19: 1-24.

FELLIZATTI, P. (1998). Aspectos fonético-fonológicos da disartria pós-traumática: um estudo de caso. Dissertação de mestrado inédita. IEL/ UNICAMP.

GRODZINSKY, Y. (1990). Theoretical perspectives on language deficits. Cambridge, Massachussetts, The M.I.T. Press.

JAKOBSON, R. (1968). Child language, aphasia and phonological universals. Haia, Mouton. 
LAVER, J. (1980). The phonetic description of voice quality. Cambridge: Cambridge University Press.

MOER, I. \& SUNDET, K. (1996). Production and perception of word tones (pitch accents) in patients with left and right hemisphere damage. Brain and language, 53, 267-281.

MORATO, E. \& FREITAS, M. (1993). Algumas questões sobre prosódia no contexto neurolingüístico. Cadernos de Estudos Lingüísticos, IEL/UNICAMP.

NESPOR, M. \& VOGEL, I. (1986). Prosodic phonology. Dordrecht, Foris Publications.

NICKELS, L \& HOWARD, D. (1999). Effects of lexical stress on aphasic word production. Clinical Linguistics and Phonetics, vol. 13, $\mathrm{n}^{\circ} 4$.

SCARPA, E.M. (2000). O recurso a níveis prosódicos superiores na aquisição e na afasia. PaLavra, $\mathrm{n}^{\circ}$ 6, 48-62. PUC, Rio de Janeiro.

SCARPA, E.M. (no prelo). Dificuldades prosódicas em sujeitos cérebro-lesados. Revista ALFA, UNESP (volume em homenagem a Francisco da Silva Borba) .

SELKIRK, E. (1984). Phonology and syntax. The relation between sound and structure. Cambridge, Mass.: M.I.T. Press

WERNIGE, D (1993). Disorders of prosody in aphasia. In: Blanken, G.; Dittmann, J.; Grimm, H.; Marshall, J. \& C-W. Wallesch (orgs.). Linguistic disorders and pathologies. An International Handbook. Berlim, Walter de Gruyter. 